\title{
MicroRNA-125b Suppresses Ovarian Cancer Progression via Suppression of the Epithelial-Mesenchymal Transition Pathway by Targeting the SET Protein
}

\author{
Xiaoyan Ying ${ }^{a}$ Kuang Wei $j^{a}$ Zhe Lin ${ }^{b}$ Yugui Cuic Jie Ding ${ }^{a}$ Yun Chen ${ }^{b}$ Boqun Xua \\ aDepartment of Obstetrics and Gynecology, Second Affiliated Hospital of Nanjing Medical University, \\ Nanjing, 'Department of Immunology, Nanjing Medical University, Nanjing, 'The State Laboratory of \\ Reproductive Medicine, Clinical Center of Reproductive Medicine, First Affiliated Hospital, Nanjing \\ Medical University, Nanjing, China
}

\section{Key Words}

Epithelial ovarian cancer • MicroRNA-125b - SET protein • Epithelial-mesenchymal transition

\begin{abstract}
Background/Aims: MicroRNA-125b (miR-125b) is overexpressed in several types of cancer and contributes to chemotherapy resistance. However, its role in epithelial ovarian carcinoma remains unknown. The goal of this study was to identify the relationship between miR-125b and the epithelial-mesenchymal transition (EMT) in ovarian cancer. Methods: In total, 55 patients with epithelial ovarian cancer (EOC) were included in our study. The relative expression of miR-125b was measured using real-time polymerase chain reaction (RT-PCR).The protein expression of SET and EMT-related indicators in cell lines were assessed by Western blot. The regulation of SET by miR-125b was confirmed using luciferase reporter assays. The effect of miR-125b on metastasis was evaluated using an in vivo metastasis model. Results: miR-125b expression was markedly lower in the EOC specimens. Ectopic expression of miR-125b in EOC cells significantly inhibited tumor invasion.miR-125b expression was negatively associated with both EMT and SET expression, in vivo and in vitro. Mechanistic studies identified SET as a direct target of miR-125b, and the downregulation of SET, observed during tumor migration, was affected by the overexpression of miR125b. Conclusion: miR-125b suppresses EOC cell migration and invasion by targeting the SET protein, and this study may provide a novel mechanism for understanding the progression of EOC.

\section{Introduction}

Epithelial ovarian cancer (EOC) constitutes the overwhelming majority (90\%) of ovarian malignancies and is unique in clinical occurrence and metastasis. Most EOC patients

X. Ying and K. Wei contributed equally to this paper. 
are diagnosed with advanced-stage EOC due to a lack of appropriate screening methods to detect early stage EOC [1-4]. Given the difficulty of early stage diagnosis, more sensitive biomarkers should be used for the diagnosis of EOC, especially in the early stages, and the mechanistic relationship between such biomarkers and the development of EOC should be thoroughly explored.

Recently, aside from the traditional transcriptional genes, non-transcriptional RNAs, including lncRNA and miRNA, have gradually been revealed to be of great potential use in the diagnosis of different cancers, including EOC $[5,6]$.

An increasing number of studies have identified several miRNAs that are remarkably deregulated in EOC, suggesting that miRNAs are involved in the initiation and progression of this disease [7-9]. miR-125b was one such microRNA reported to be seriously associated with tumor biology. The miR-125b family consists of two members: hsa-miR-125b-1 and hsa-miR-125b-2, transcribed from two loci on chromosomes 11q24 and 21q21, respectively [10]. miR-125b is highly conserved in diverse species, from nematodes to humans. It is overexpressed in several types of cancer and has been reported to be associated with tumor resistance to chemotherapy $[10,11]$. Veerla et al. reported that the downregulation of miR-125b contributes to aggressive growth behavior in urothelial tumors [12], and Alpini et al. showed that miR-125b may inhibit the invasion, migration and angiogenesis of liver cancer and cutaneous squamous cell carcinoma cells [13, 14]. Moreover, Zhou et al. also demonstrated that the overexpression of miR-125b can inhibit EMT in hepatocellular carcinoma (HCC) [15].

The SET protein was reported to be capable of inhibiting the acetylation of nucleosomes, especially histone H4, via histone acetylases (HAT). This inhibition was most likely accomplished by masking the histone lysines from acetylation, consequently silencing HATdependent transcription [16]. The knockdown of SET inhibits cell migration and invasion by increasing the activity and expression of PP2Ac and decreasing the expression of matrix metalloproteinase 9 (MMP-9) [17]; low levels of SET expression are associated with bone metastasis in renal cell carcinoma [18]. Therefore, using a bioinformatics prediction, we found that SET was a potential target of miR-125b; therefore, we sought to assess the expression of miRNA, its effect in human EOC, and its association with SET expression and epithelial-mesenchymal transition (EMT) in human EOC.

\section{Materials and Methods}

\section{Tissue samples and cell culture}

Human ovarian cancer samples were collected from 55patients after surgical resection at the Affiliated Nanjing Second Hospital of Nanjing Medical University between 2007 and 2014. No patients had received therapy before resection. Tumor tissues and the corresponding adjacent normal tissues were frozen in liquid nitrogen and stored at $-80^{\circ} \mathrm{C}$ until RNA extraction. Written informed consent was obtained from the patients for the biological studies. This study was approved by the Ethics Committee of Nanjing Medical University. The pathological classification of ovarian cancer was determined according to the International Federation of Gynecology and Obstetrics (FIGO) system. The characteristics of the 55 EOC patients are listed in Table 1.

The EOC cell line SKOV3 was purchased from American Tissue Type Collection (Manassas, VA) and was maintained in RPMI-1640 (Sigma-Aldrich, St Louis, MO, USA) supplemented with $10 \%$ fetal bovine serum (Hyclone) at $37^{\circ} \mathrm{C}$ and a humidified atmosphereof $5 \% \mathrm{CO}_{2}$.

RNA extraction and analysis using quantitative real-time PCR ( $q R T-P C R$ )

For miRNA quantification, the total RNA from cell lines and tissues was extracted using TRIzol reagent (Invitrogen) according to the manufacturer's instructions. The Hairpin-it ${ }^{\mathrm{TM}}$ miRNAs qPCR Quantitation Kit (GenePharma, China) was used for miR-125b analysis. This kit contains a highly miRNA-specific RT and PCR primer set with SYBR Green dye included. The RT primer for the stem-loop-like miRNAs and the highly specific primer set for miRNAs ensure that the RT and PCR reaction proceed without interference from the miRNA precursors.

\section{KARGER}




\section{Cellular Physiology Cell Physiol Biochem 2016;39:501-510 \begin{tabular}{l|l|} 
and Biochemistry 10.1159/000445642 & $\begin{array}{l}\text { DO 2016 The Author(s). Published by S. Karger AG, Basel } \\
\text { www.karger.com/cpb }\end{array}$
\end{tabular} \\ Ying et al.: MiR-125b Regulates EOC Metastasis via SET}

For the detection of SET expression, the following primers were used: SET forward (5'-GUC CCA CUG UCA UGU AAA UTT- $\left.3^{\prime}\right)$ and reverse ( $5^{\prime}$-AUU UAC AUG ACA GUG GGA CTT- $3^{\prime}$ ). miRNA and mRNA were normalized to U6 and GAPDH, respectively. All RT-PCR experiments were performed using a Bio-Rad CFX96 Real-Time PCR Detection System (Bio-Rad, Hercules, CA, USA). The expression levels relative to U6 and GAPDH were calculated using the $2^{-\Delta \Delta C T}$ formula.

Vector construction and 3-UTR luciferase reporter assay

Overexpression and inhibition of miR$125 \mathrm{~b}$ were assessed using miR125b,miR$125 \mathrm{~b}$ human mimics inhibitor, miR-125b human inhibitor and the negative control FAM, purchased from GenePharma(China).The 3'-UTR region of SET containing the wild-type or mutant potential target site for miR-125b (SET-wt 3'-UTR or SET-mut 3'-UTR, respectively) was synthesized and inserted into the pEZX-MT01 vector (GeneCopoeia). For the luciferase assay, SKOV3 cells were co-transfected with SET-wt 3'-UTR or SET-mut 3'-UTR and the miR-125b mimics, inhibitor or control (GenePharma, China) using Lipofectamine 2000 (Invitrogen). Cells were harvested $48 \mathrm{~h}$ after transfection for the luciferase assay using a Luc-Pair ${ }^{\mathrm{TM}}$ miR Luciferase Assay Kit (GeneCopoeia) according to the manufacturer's protocol.

\section{Western blot analysis}

For western blot analysis, cells were lysed in lysis buffer after being washed with PBS containing a protease inhibitor. Proteins were separated by SDS-PAGE on a $10 \%$ gel and were transferred to polyvinylidene difluoride (PVDF) membranes (Millipore). After $1 \mathrm{~h}$ of blocking with $5 \%$ non-fat dry milk at room temperature, the blots were incubated with primary antibody overnight at $4^{\circ} \mathrm{C}$, followed by four $5 \mathrm{~min}$ washes in TBST and incubation with the corresponding secondary antibody for $2 \mathrm{~h}$ at room temperature. The proteins were visualized in the membranes using enhanced chemiluminescence solutions (Bio-Rad, Hercules, CA, USA), and Image J software (National Institutes of Health, USA) was used to measure the band intensities. Primary antibodies used and their dilutions are as follows: anti-SET (1:2000), anti-GAPDH (1:5000) (Abcam, Cambridge Science Park, Cambridge, UK), anti-E-cadherin (1:1000),anti-N-cadherin (1:1000), and anti-vimentin (1:1000) (Cell Signaling Technology, Inc., Danvers, MA, USA). The secondary antibody was a goat anti-rabbit antibody (1:2000) (Santa Cruz Biotechnology, Inc.).

\section{Cell invasion and scratch wound assay}

In the invasion assay, cell culture inserts (8.0- $\mu \mathrm{m}$ pores, Millipore, USA) were coated with Matrigel diluted 1:6 in serum-free medium. In total, 5000 cells were resuspended in serum-free medium and placed in the upper chamber, and $500 \mu \mathrm{L}$ medium with 10\% FBS was added to the lower chambers. After $24 \mathrm{~h}$, the cells that had not migrated or invaded were removed using a cotton swab; then, the insert was fixed in $4 \%$ paraformaldehyde for $30 \mathrm{~min}$ at room temperature, stained with $0.1 \%$ crystal violet, and counted under an inverted microscope. Cells were seeded in 6-well plates, and the confluent monolayer of cells was scratched using a sterile $100 \mu \mathrm{L}$ pipette tip. Medium was added, and the culture plates were incubated at $37^{\circ} \mathrm{C}$. Images of the scratch wound were taken using a digital camera (Olympus Corporation, Japan) $24 \mathrm{~h}$ later. We repeated all experiments three times.

\section{CCK-8 assay for cell proliferation}

In each group, cells were seeded at $1 \times 10^{4}$ per well in 96-wellplates and were cultured in RPMI-1640 medium supplemented with $10 \%$ FBS at $37^{\circ} \mathrm{C}$ and $5 \% \mathrm{CO}_{2}$ for $24 \mathrm{~h}$. CCK-8 reagent (Keygen) (10 $\left.\mu \mathrm{L}\right)$ was added to the maintenance cell medium at different time points and was incubated with the cells at $37^{\circ} \mathrm{C}$ for 


\section{Cellular Physiology Cell Physiol Biochem 2016;39:501-510 \begin{tabular}{l|l} 
and Biochemistry Published online: July 07, 2016 & $\begin{array}{l}\text { DO } 2016 \text { The Author(s). Published by S. Karger AG, Basel } \\
\text { www.karger.com/cpb }\end{array}$ \\
\hline
\end{tabular} \\ Ying et al.: MiR-125b Regulates EOC Metastasis via SET}

an additional $4 \mathrm{~h}$. Absorbance values were determined by using amicroplate reader (ASYS Hitech Gmbh, CliniBio 128C) at $450 \mathrm{~nm}$.

Apoptosis assay

Cell apoptosis was measured using the Annexin V-FITCkit (Miltenyi Biotec). Cells were harvested at $48 \mathrm{~h}$ post-transfection, washed twice with PBS, resuspended in $100 \mu$ Lof $1 \times$ binding buffer and then stained with $5 \mu \mathrm{L}$ of Annexin V-FITC. After $15 \mathrm{~min}$ at room temperature in the dark, the cells were resuspended in $500 \mu \mathrm{L}$ of the $1 \times$ binding buffer. A total of $3 \mu \mathrm{L}$ of PI solution was added immediately prior to analysis by flow cytometry (FACSCalibur, BD Biosciences, USA).

\section{Mouse model}

Nude mice were purchased from Vital River Laboratories (Beijing, China). All animals were used in accordance with the institutional guidelines, and the current experiments were approved by the Use Committee for Animal Care. SKOV3 cells were transfected with the vector control, miR-125b mimic or inhibitor. All cultures used for tail injection were sub-confluent and were fed the day prior to their use. The harvested cell suspension was washed twice by centrifugation in medium containing serum at room temperature and then resuspended in medium without serum at $4{ }^{\circ} \mathrm{C}$ immediately prior to injection. The cells $\left(1 \times 10^{6}\right.$ cells $)$ to be injected were suspended in $0.1 \mathrm{ml}$ PBS. The animals were sacrificed 6 weeks after the injections. Pictures were recorded using a Nikon d800 digital camera (Nikon, Tokyo, Japan).

\section{Statistical analyses}

All statistical analyses were performed using SPSS for Windows, v.18.0 (SPSS, Chicago, IL).P-values less than 0.05 were considered statistically significant $(\mathrm{P}<0.05)$, and graphs were plotted using GraphPad Prism 5.02. Comparisons between groups were performed using the Kruskal-Wallis test for continuous variables and the chi-square $\left(\chi^{2}\right)$ test for categorical variables.

\section{Results}

miR-125b is downregulated in EOC tissues

The miR-125b expression level was examined using qRT-PCR in ovarian tissues obtained from 55 ovarian cancer patients and was normalized to GAPDH. Ourdata indicated that miR-125bexpression was lower in ovarian cancer tissues (Fig. 1A and B). Furthermore, we analyzed the correlation between the miR-125b expression and the clinicopathological characteristics and found that the expression ofmiR-125b was significantly higher in tumors at an earlier FIGO stage (StageI-II). The other clinicopathological characteristics, including age, histological type and tumor grade, did not have a statistically significant effect (Table 1).

To determine the cellular localization of the SET protein and EMT-related indicators in the human ovaries, immunohistochemical analysis was performed, as shown in the typical sample pictures in Fig. 1. Expression of the SET protein in ovarian cancer was clearly higher than that in normal ovaries (Fig. 1C, D).The EOC group was divided into two subgroups according to the expression of miR-125b. The group with high miR-125b expression also had low expression of SET and epithelia cadherin (E-cad), which is a hallmark of the epithelial layer; in contrast, the group with low miR-125b expression had relatively high expression levels of SET and E-cad. Furthermore, a linear correlation test was performed using the expression of SET and E-cad as well as that of SET and miR-125b; the results suggested that SET expression was positively and negatively related to E-cad and miR-125b expression, respectively (Fig. 1C,D).

\section{miR-125b binds directly to the SET 3'-UTR to regulate SET expression}

To determine whethermiR-125bregulates SET expression, the binding of miR-125b to the 3'-UTR region of SET was first evaluated using online bioinformatics tools (Fig. 2A, B). Then, we co-transfected a miR-125b mimic or inhibitor with a dual-luciferase reporter construct containing either thewild-type or a mutant SET 3'-UTR.The results showed that 
Fig. 1. MiR-125bexpression is dramatically attenuated in EOC tissues and is negatively correlated with SET and EMT. (A-B) Transcription of miR-125b and SET in EOC and normal ovaries tissues was determined by real-time PCR. The subdivision of EOC patients by miR-125b expression was based on a 95\% CI. (C) Expression of SET protein in EOC and normal ovaries by western blot assay. (D) Representative images of IHC staining for SET or EMT markers (E-cad) in the high or low miR-125b subgroups in EOC or normal tissues; linear correlation studies were performed between SET vs. E-cad and miR$125 \mathrm{~b}$ vs. SET.

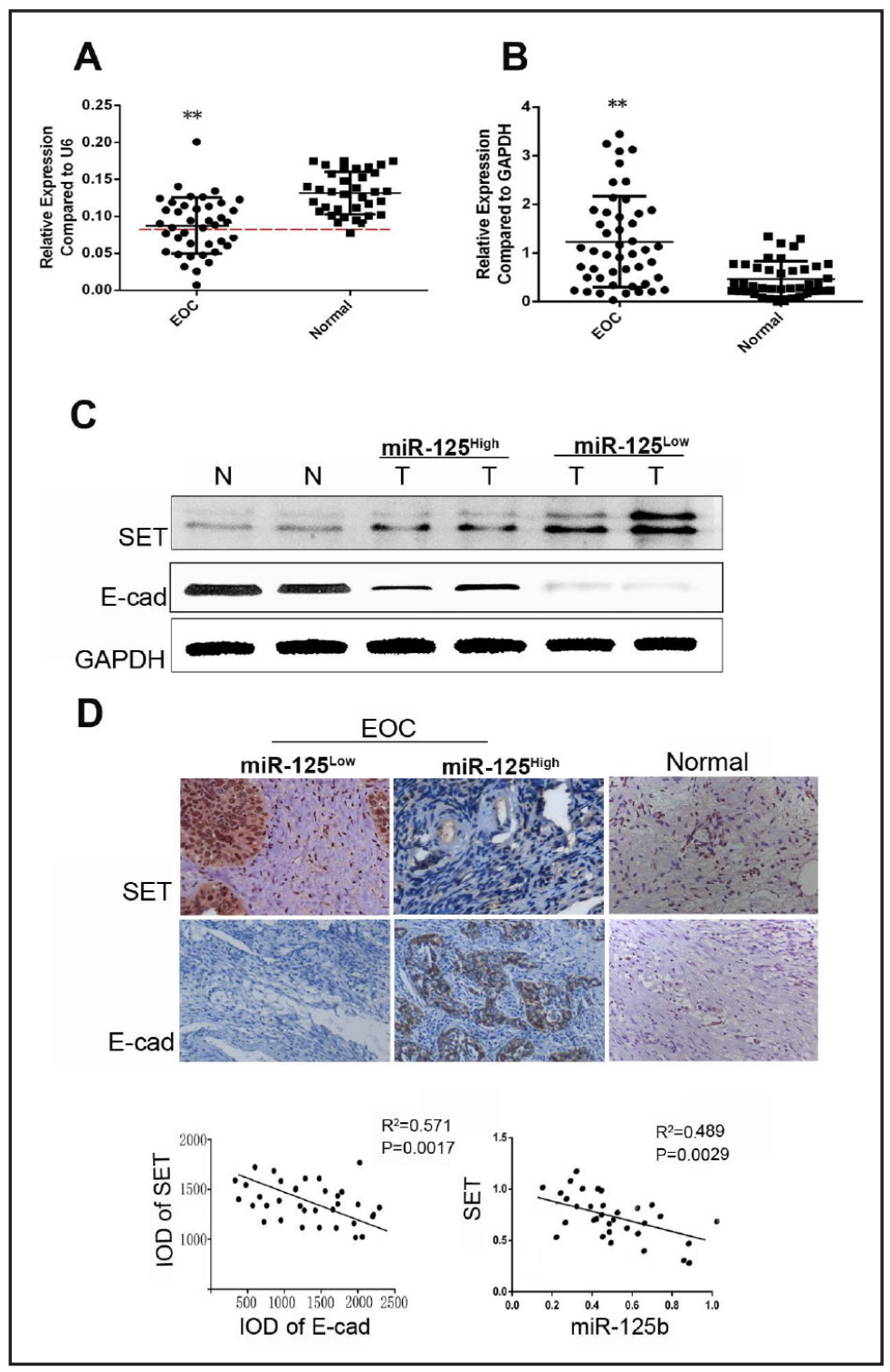

the mimic reduced luciferase activity by $54 \%$ compared with the inhibitor and also had lower luciferase activity than the empty vector control (Fig. 2C). These data demonstrate that miR-125b can combine with the 3'-UTR region of SET to inhibit gene expression and that the mutated region may eliminate this inhibitory effect.

\section{miR-125b inhibits SKOV3migration and invasion in vitro}

The vast majority of deaths from cancer are due to metastasis, and having ascertained the relationship between miR-125b expression and metastasis, we therefore investigated whether reintroducing miR-125b would decrease the invasive and migration potential of SKOV3 cells. To investigate the effects of miR-125b on EOC invasion, SKOV3 cells were transfected with a miR-125b human mimic, an inhibitor or a negative control (NC). The invasion capacity was measured via transwell. Overexpression of miR-125bcan significantly weaken cell invasion capabilities compared with the inhibitor group (Fig. 3A, B). Scratch assays showed that the group transfected with the miR-125b mimic significantly decreased cell invasion, while cell invasion was apparently suppressed by using an miR-125b inhibitor (Fig. 3C, D). Therefore, these data indicate that miR-125b is involved in the regulation of EOC invasion and migration. 


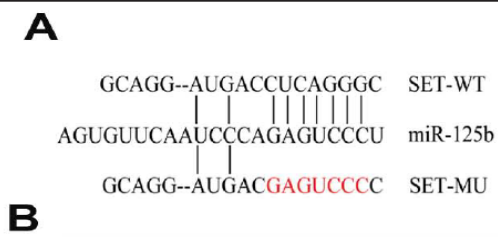

$>10$

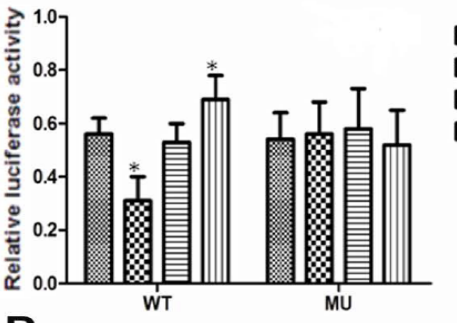

D
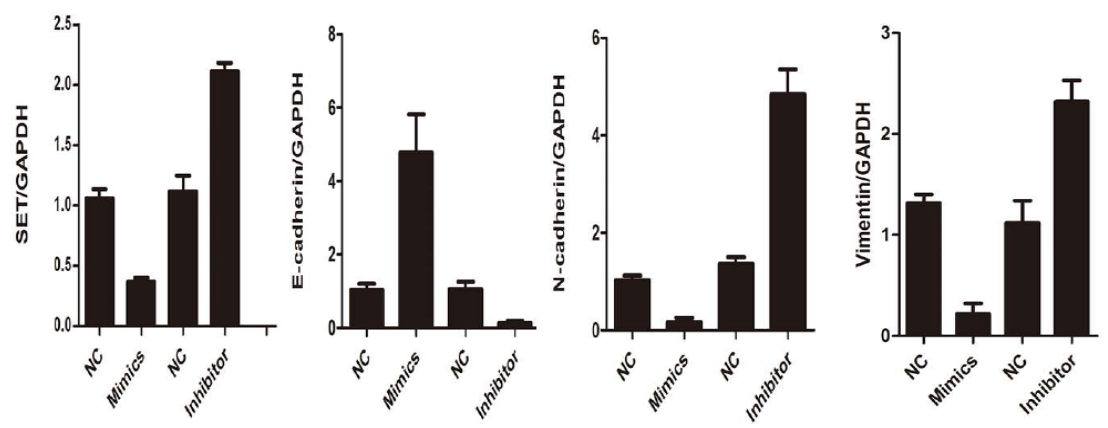

Fig. 2. Overexpression of miR-125b inhibits the EMT pathway. Left panel: The sequence alignment of human miR-125b matches the3'-UTR of SET. Bottom: mutations of the 3'-UTR of SET used to create the mutant luciferase reporter construct. Right panel: Map of the human miR-125b genomic region with the phylogenetically conserved SET-binding site indicated. (B) SKOV3 cells were transfected with miR-125b human mimics, an inhibitor, or their respective negative controls. (D-E) The expression of SET, E-cad, N-cad and Vimentin was analyzed by western blotting. Representative blots and the results of the analyses are shown $\left({ }^{*} P<0.05\right)$.

Fig. 3. Cell invasion and migration are inhibited by miR-125b in SKOV3 cells. (A and C) Matrigel invasion assay and scratch wound healing assay were performed to investigate the changes in cell invasion and migration. (B and D) The bar graph shows quantification of the cell invasion or migration of the miR-125b mimics-transfected and inhibitor-transfected cells. Statistical results of three independent experiments are shown.

miR-125b cannot affect the proliferation and apoptosis of EOC cells

To investigate whether miR$125 \mathrm{~b}$ affects the proliferation and apoptosis of EOC cells, SKOV3 cells transfected as described above were analyzed by Annexin V-FITC/PI

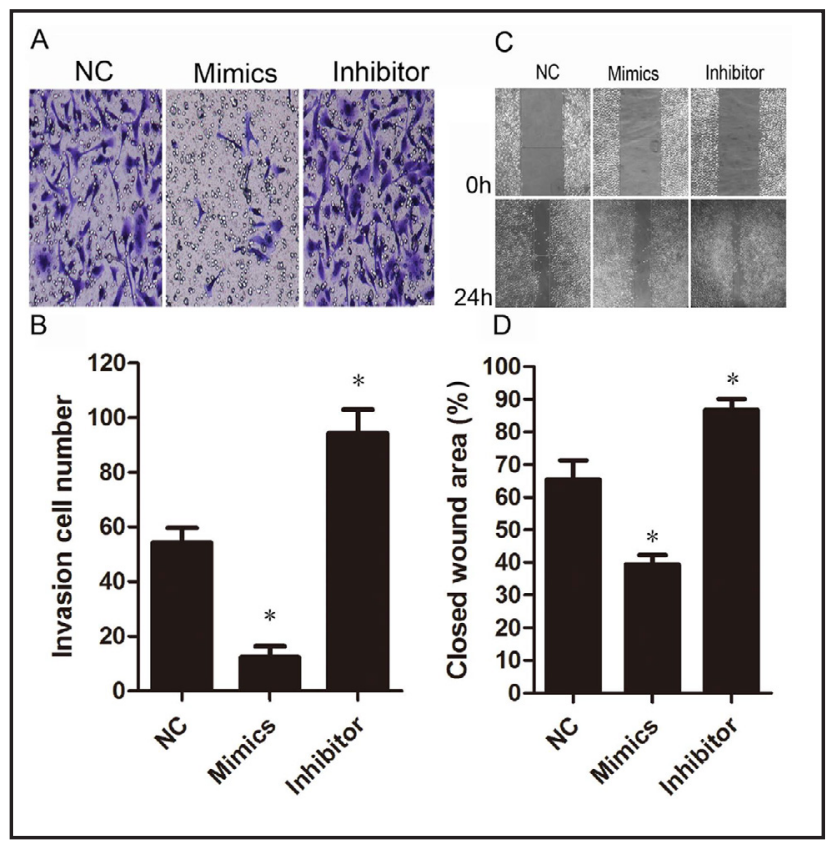


Fig. 4. MiR-125b has no effect on the proliferation and apoptosis of EOC cells. (A) Apoptosis rate of the cells was detected by flow cytometry. UR: dead cells; LR: apoptotic cells; LL: viable cells. (B) The apoptosis rate was not significantly different among the groups. (C) The fold increase in cell proliferation was tested using CCK-8at 24h intervals. The miR-125b human mimics group did not have a significantly different growth rate compared with the inhibitor or negative control groups in SKOV3 cells. (D) Protein expression of the SKOV3 cells in (A) in each group was detected by western-blot.

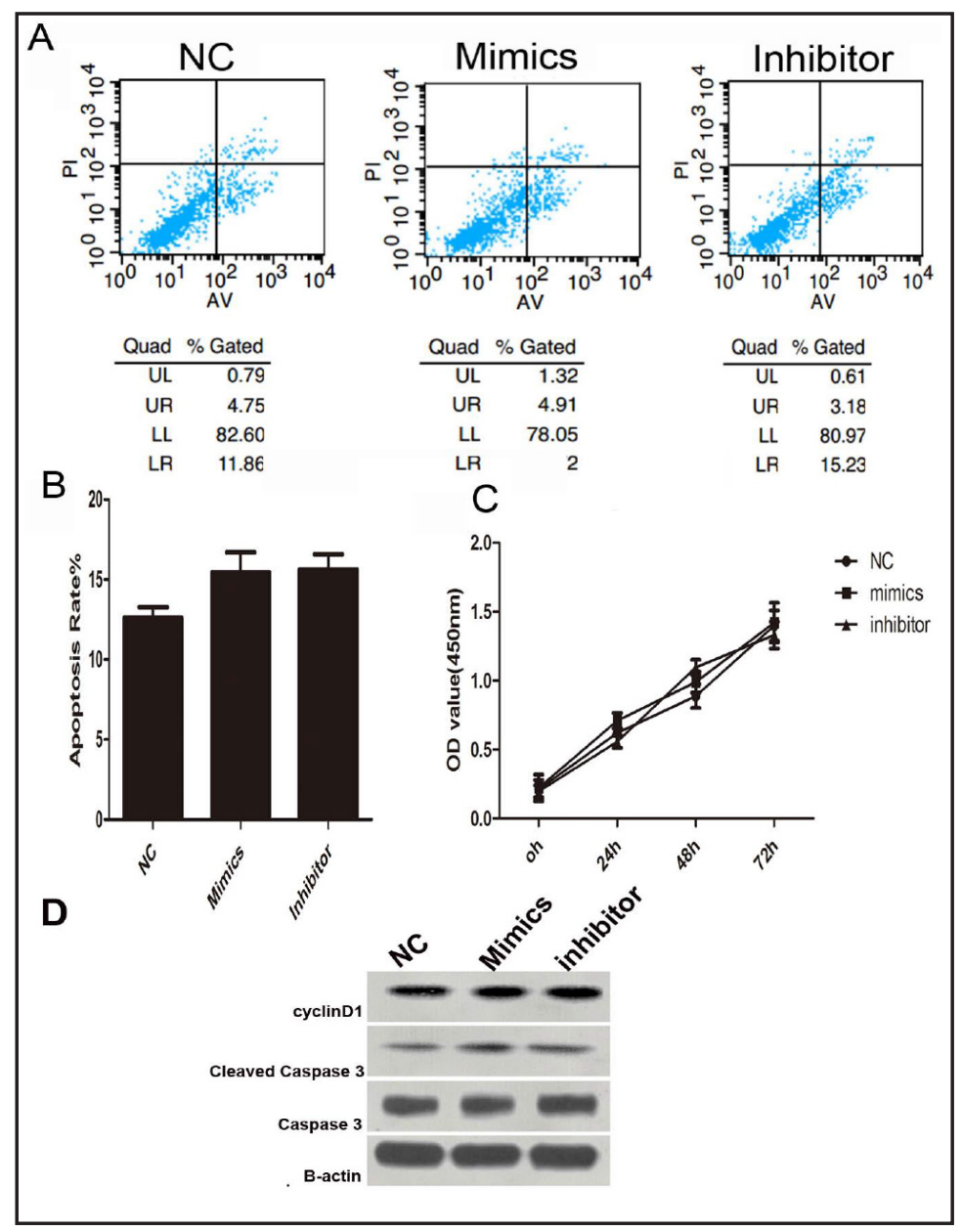

staining. The results showed that overexpression or downregulation of miR-125b had no apparent effect on either apoptosis or cell proliferation (Fig. 4A, B). Furthermore, proteins that indicate cell proliferation and apoptosis, such as cyclinD1 and cleaved caspase-3, were detected, revealing that miR-125b has no significant impact on cell proliferation and apoptosis (Fig. 4D). The fold increase in cell proliferation was tested using CCK-8at 24-h intervals. The miR-125b human mimics group did not show a significantly different growth rate compared with the inhibitor or the negative control group in SKOV3 cells (Fig. 4C).

\section{miR-125b inhibits SKOV3 migration and invasion in vivo}

To investigate the role of miR-125b in inhibiting migration, anin vivo assay was performed using tail injections in a nude mouse model; several metastases were found in the WT control group due to the invasive nature of the SKOV3 cells. However, metastasis was almost entirely inhibited when miR-125b was overexpressed in such cells; moreover, significantly increased metastasis was found when the inhibitor of miR-125b was used. In addition, the tumor volume of each group was determined, and no significant difference was found among the three groups (Fig. 5A). The expression of SET- and EMT-related indicators were detected in both the primary tumor and the metastases. Within the primary tumor, as in the in vitro assay, SET expression was enhanced in the mimic group and dramatically attenuated in the inhibitor group, and EMT indices, such as the epithelial marker E-cad, were decreased in the mimic group and in the inhibitor group. In contrast, the mesenchymal marker Vim was increased in the mimic group and was lower in the inhibitor group. Within the metastases, the EMT shift was more apparent in the inhibitor group than in the WT control (Fig. 5B). 
Fig. 5. $M i R-125 b$ inhibited tumor metastasis in vivo. (A) Tumorigenesis assay using luciferase-transfected SKOV3 cells via tail vein injection in nude mice. The representative figure is presented in the left panel, and a comparison of metastases in the groups listed is presented in the right panel. (B) Protein expression of the indicated genes in three different subsets was analyzed by western blot in the primary tumor and in the metastases.
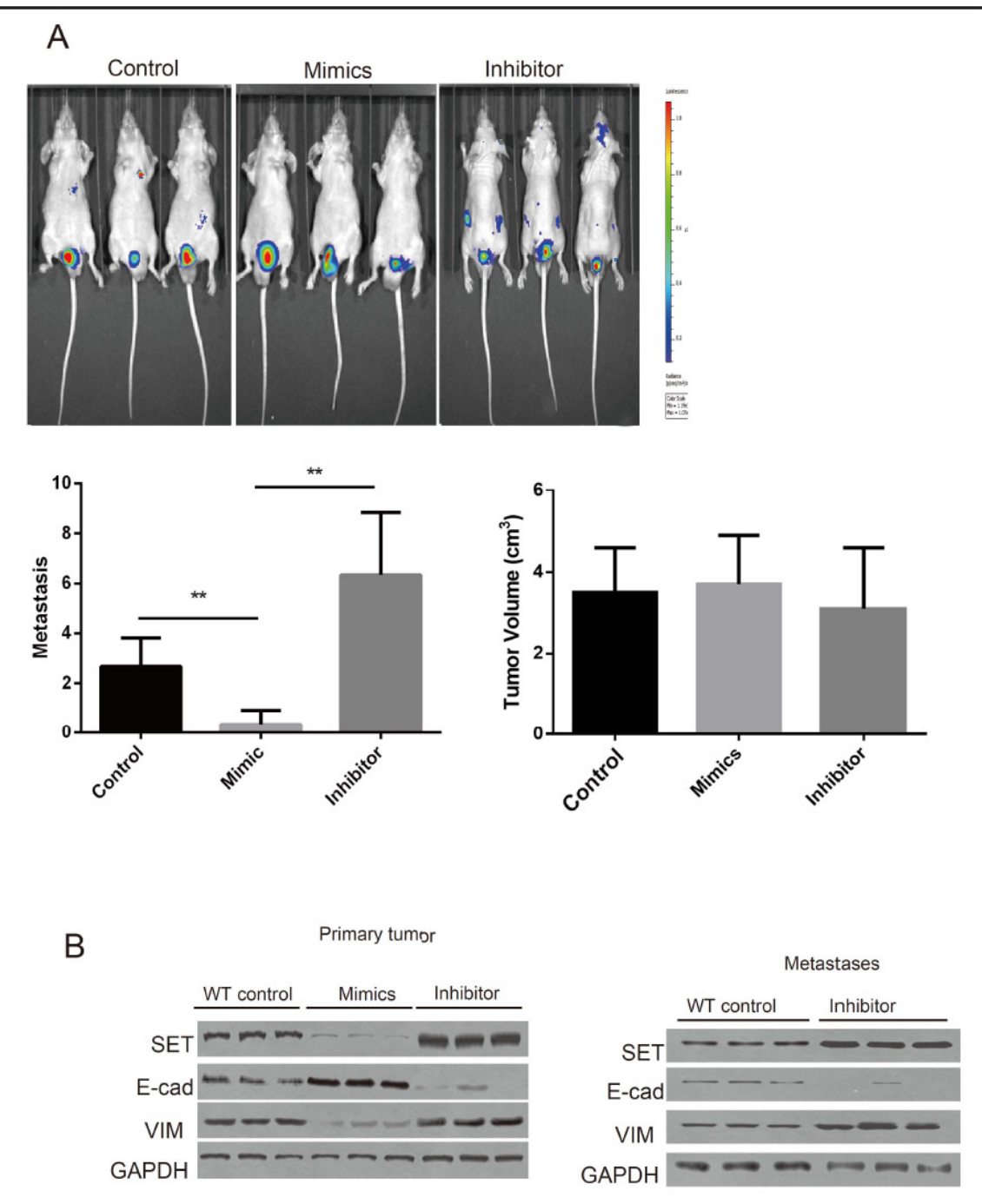

\section{Discussion}

Ovarian cancer is a highly lethal disease that lacks effective screening tests for early detection $[19,20]$. Most ovarian cancers are diagnosed at an advanced stage when the tumor is largely metastatic $[1,21]$. Recently, increasing data have indicated that non-coding RNAs, including lncRNA and miRNA,are crucial in the regulation of essential functional genes related to the biological features of invasion, such as EMT [22-24]. This study demonstrates that miR-125b is a tumor suppressor in EOC by inhibiting EMT and directly targeting SET. Moreover, we demonstrated that the downregulation of miR-125b was linked to cell invasion and migration and tumor occurrence, and low expression of miR-125b was associated with advanced FIGO stage (Stage III-IV), which was followed by experimental validation in cell culture studies and clinical data.

MicroRNAs (miRNAs) are endogenous, single-stranded, non-coding, small RNAs that regulate gene expression by preferentially binding to specific sequences in the $3^{\prime}$-untranslated region (3'-UTR) of their target mRNAs [25-27]. In the present study, miR$125 \mathrm{~b}$ was found to be associated with tumor metastasis by controlling the EMT by regulating the SET gene through 3'-UTR binding. This outcome was similar to the findings of Zhou et al., who indicated that miR-125b may exert inhibitory effects on EMT in liver cancer cells by SMAD2 and that EMT could play an important role in ovarian cancer tumorigenesis [15].

\section{KARGER}




\section{Cellular Physiology Cell Physiol Biochem 2016;39:501-510 \begin{tabular}{l|l|l|}
\hline DOI: 10.1159/000445642 & $\begin{array}{l}\text { C) } 2016 \text { The Author(s). Published by S. Karger AG, Basel } \\
\text { www.karger.com/cpb }\end{array}$ \\
\hline Published online: July 07,2016 Biochemistry
\end{tabular} \\ Ying et al.: MiR-125b Regulates EOC Metastasis via SET}

Based on the clinical samples from55 cases of ovarian cancer, low expression of miR125bis associated with higher FIGO grades. Interestingly, other researchers have found that miR-125b expression in epithelial ovarian cancer cells and tissues is significantly decreased [23]. In addition, the expression of miR-125b was negatively related to SET expression and the degree of EMT, and themechanism involved was verified by both in vivo and in vitro assays showing that miR-125b can downregulate SET transcription and therefore attenuate EMT in ovarian cells. SET overexpression promotes cancer cell invasion and migration and is significantly associated with androgen production by ovarian follicles in vitro [28].

SET is widely expressed in many tissues, such as adrenal glands, gonads and the central nervous system $[29,30]$. The SET protein belongs to a family of multitasking proteins, also known as TAF-1 $\beta$, I2PP2A and INHAT, which are involved in apoptosis, transcription, nucleosome assembly, and histone binding [31,32]. This nuclear phosphoprotein encoded by the translocation breakpoint has been proven to be associated with acute myelogenous leukemia $[16,33]$.

Thus, these studies not only substantially broaden our understanding of the complex mechanisms underlying the pathogenesis of EOC but also suggest potential new interventional and therapeutic strategies.

\section{Acknowledgements}

This work was supported by grants from the National Natural Science Foundation (31301182 to BX, 81272322 to YC and 81370754 to YGC), the Qing Lan Project, the Six Talent Peaks Project (JY-018), and the Student Innovation Training Program of Jiangsu Province.

\section{References}

1 Jayson GC, Kohn EC, Kitchener HC, Ledermann JA: Ovarian cancer. Lancet 2014;384:1376-1388.

2 Coleman RL, Monk BJ, Sood AK, Herzog TJ: Latest research and treatment of advanced-stage epithelial ovarian cancer. Nat Rev Clin Oncol 2013;10:211-224.

3 Vaughan S, Coward JI, Bast RC, Jr., Berchuck A, Berek JS, Brenton JD, Coukos G, Crum CC, Drapkin R, Etemadmoghadam D, Friedlander M, Gabra H, Kaye SB, Lord CJ, Lengyel E, Levine DA, McNeish IA, Menon U, Mills GB, Nephew KP, Oza AM, Sood AK, Stronach EA, Walczak H, Bowtell DD, Balkwill FR: Rethinking ovarian cancer: Recommendations for improving outcomes. Nat Rev Cancer 2011;11:719-725.

4 Yeung TL, Leung CS, Yip KP, Au Yeung CL, Wong ST, Mok SC: Cellular and molecular processes in ovarian cancer metastasis. A review in the theme: Cell and molecular processes in cancer metastasis. Am J Physiol Cell Physiol 2015;309:C444-456.

5 Chen Q, Qin R, Fang Y, Li H: Berberine sensitizes human ovarian cancer cells to cisplatin through mir-93/ pten/akt signaling pathway. Cell Physiol Biochem 2015;36:956-965.

6 Ge T, Yin M, Yang M, Liu T, Lou G: Microrna-302b suppresses human epithelial ovarian cancer cell growth by targeting runx1. Cell Physiol Biochem 2014;34:2209-2220.

7 Yang H, Kong W, He L, Zhao JJ, O'Donnell JD, Wang J, Wenham RM, Coppola D, Kruk PA, Nicosia SV, Cheng JQ: Microrna expression profiling in human ovarian cancer: Mir-214 induces cell survival and cisplatin resistance by targeting pten. Cancer Res 2008;68:425-433.

8 Dutta S, Wang FQ, Phalen A, Fishman DA: Biomarkers for ovarian cancer detection and therapy. Cancer Biol Ther 2010;9:668-677.

9 Yao J, Zhou B, Zhang J, Geng P, Liu K, Zhu Y, Zhu W: A new tumor suppressor lncrna adamts9-as2 is regulated by dnmt1 and inhibits migration of glioma cells. Tumour Biol 2014;35:7935-7944.

10 Yin H, Sun Y, Wang X, Park J, Zhang Y, Li M, Yin J, Liu Q, Wei M: Progress on the relationship between mir125 family and tumorigenesis. Exp Cell Res 2015;339:252-260.

11 Shaham L, Binder V, Gefen N, Borkhardt A, Izraeli S: Mir-125 in normal and malignant hematopoiesis. Leukemia 2012;26:2011-2018. 


\section{Cellular Physiology Cell Physiol Biochem 2016;39:501-510 \begin{tabular}{l|l|l}
\hline DOI: 10.1159/000445642 2016 & $\begin{array}{l}\text { () 2016 The Author(s). Published by S. Karger AG, Basel } \\
\text { www.karger.com/cpb }\end{array}$ \\
\hline
\end{tabular}}

Ying et al.: MiR-125b Regulates EOC Metastasis via SET

12 Veerla S, Lindgren D, Kvist A, Frigyesi A, Staaf J, Persson H, Liedberg F, Chebil G, Gudjonsson S, Borg A, Mansson W, Rovira C, Hoglund M: Mirna expression in urothelial carcinomas: Important roles of mir-10a, mir-222, mir-125b, mir-7 and mir-452 for tumor stage and metastasis, and frequent homozygous losses of mir-31. Int J Cancer 2009;124:2236-2242.

13 Alpini G, Glaser SS, Zhang JP, Francis H, Han Y, Gong J, Stokes A, Francis T, Hughart N, Hubble L, Zhuang SM, Meng F: Regulation of placenta growth factor by microrna-125b in hepatocellular cancer. J Hepatol 2011;55:1339-1345.

14 Xu N, Zhang L, Meisgen F, Harada M, Heilborn J, Homey B, Grander D, Stahle M, Sonkoly E, Pivarcsi A: Microrna-125b down-regulates matrix metallopeptidase 13 and inhibits cutaneous squamous cell carcinoma cell proliferation, migration, and invasion. J Biol Chem 2012;287:29899-29908.

15 Zhou JN, Zeng Q Wang HY, Zhang B, Li ST, Nan X, Cao N, Fu CJ, Yan XL, Jia YL, Wang JX, Zhao AH, Li ZW, Li YH, Xie XY, Zhang XM, Dong Y, Xu YC, He LJ, Yue W, Pei XT: Microrna-125b attenuates epithelialmesenchymal transitions and targets stem-like liver cancer cells through small mothers against decapentaplegic 2 and 4. Hepatology 2015;62:801-815.

16 Li M, Makkinje A, Damuni Z: The myeloid leukemia-associated protein set is a potent inhibitor of protein phosphatase 2a. J Biol Chem 1996;271:11059-11062.

17 Li J, Yang XF, Ren XH, Meng XJ, Huang HY, Zhao QH, Yuan JH, Hong WX, Xia B, Huang XF, Zhou L, Liu JJ, Zou F: Stable set knockdown in breast cell carcinoma inhibits cell migration and invasion. Biochem Biophys Res Commun 2014;453:7-12.

18 Wang J, Zhao X, Qi J, Yang C, Cheng H, Ren Y, Huang L: Eight proteins play critical roles in rcc with bone metastasis via mitochondrial dysfunction. Clin Exp Metastasis 2015;32:605-622.

19 Landen CN, Jr., Birrer MJ, Sood AK: Early events in the pathogenesis of epithelial ovarian cancer. J Clin Oncol 2008;26:995-1005.

20 Cho KR, Shih Ie M: Ovarian cancer. Annu Rev Pathol 2009;4:287-313.

21 Song N, Liu H, Ma X, Zhang S: Placental growth factor promotes metastases of ovarian cancer through mir543-regulated mmp7. Cell Physiol Biochem 2015;37:1104-1112.

22 Yuan JH, Yang F, Wang F, Ma JZ, Guo YJ, Tao QF, Liu F, Pan W, Wang TT, Zhou CC, Wang SB, Wang YZ, Yang Y, Yang N, Zhou WP, Yang GS, Sun SH: A long noncoding rna activated by tgf-beta promotes the invasionmetastasis cascade in hepatocellular carcinoma. Cancer Cell 2014;25:666-681.

23 Iorio MV, Visone R, Di Leva G, Donati V, Petrocca F, Casalini P, Taccioli C, Volinia S, Liu CG, Alder H, Calin GA, Menard S, Croce CM: Microrna signatures in human ovarian cancer. Cancer Res 2007;67:8699-8707.

24 Xia H, Hui KM: Micrornas involved in regulating epithelial-mesenchymal transition and cancer stem cells as molecular targets for cancer therapeutics. Cancer Gene Ther 2012;19:723-730.

25 Lau NC, Lim LP, Weinstein EG, Bartel DP: An abundant class of tiny rnas with probable regulatory roles in caenorhabditis elegans. Science 2001;294:858-862.

26 Bartel DP: Micrornas: Genomics, biogenesis, mechanism, and function. Cell 2004;116:281-297.

27 Bartel DP: Micrornas: Target recognition and regulatory functions. Cell 2009;136:215-233.

28 Xu B, Gao L, Cui Y, Dai X, Li M, Zhang Y, Ma X, Diao F, Liu J: Set protein up-regulated testosterone production in the cultured preantral follicles. Reprod Biol Endocrinol 2013;11:9.

29 Compagnone NA, Zhang P, Vigne JL, Mellon SH: Novel role for the nuclear phosphoprotein set in transcriptional activation of p450c17 and initiation of neurosteroidogenesis. Mol Endocrinol 2000;14:875888.

30 Zhang P, Compagnone NA, Fiore C, Vigne JL, Culp P, Musci TJ, Mellon SH: Developmental gonadal expression of the transcription factor set and its target gene, p450c17 (17alpha-hydroxylase/c17,20 lyase). DNA Cell Biol 2001;20:613-624.

31 Ichijo T, Chrousos GP, Kino T: Activated glucocorticoid receptor interacts with the inhat component set/tafibeta and releases it from a glucocorticoid-responsive gene promoter, relieving repression: Implications for the pathogenesis of glucocorticoid resistance in acute undifferentiated leukemia with set-can translocation. Mol Cell Endocrinol 2008;283:19-31.

32 Trotta R, Ciarlariello D, Dal Col J, Allard J, 2nd, Neviani P, Santhanam R, Mao H, Becknell B, Yu J, Ferketich AK, Thomas B, Modi A, Blaser BW, Perrotti D, Caligiuri MA: The pp2a inhibitor set regulates natural killer cell ifn-gamma production. J Exp Med 2007;204:2397-2405.

33 Arnaud L, Chen S, Liu F, Li B, Khatoon S, Grundke-Iqbal I, Iqbal K: Mechanism of inhibition of pp2a activity and abnormal hyperphosphorylation of tau by i2(pp2a)/set. FEBS Lett 2011;585:2653-2659. 